\title{
Universiteit
}

Leiden

The Netherlands

\section{Abui Tripartite Verbs: Exploring the limits of compositionality} Klamer, Marian; Kratochvil, F.; Wohlgemuth Jan, Cysouw Michael

\section{Citation}

Klamer, M., \& Kratochvil, F. (2010). Abui Tripartite Verbs: Exploring the limits of compositionality. In C. M. Wohlgemuth Jan (Ed.), Rara and Rarissima: Documenting the fringes of linguistic diversity (pp. 209-233). Berlin New York: Mouton de Gruyter. Retrieved from https://hdl.handle.net/1887/18299

Version: $\quad$ Not Applicable (or Unknown)

License: $\quad$ Leiden University Non-exclusive license

Downloaded from: https://hdl.handle.net/1887/18299

Note: To cite this publication please use the final published version (if applicable). 


\title{
Abui tripartite verbs: exploring the limits of compositionality
}

\author{
Marian Klamer \& František Kratochvíl
}

\section{Introduction}

Abui is a non-Austronesian (Papuan) language spoken in the Alor-Pantar Archipelago in Eastern Indonesia by about 16.000 people. A linguistic description of the northern Abui dialects is available (Stokhof 1984; Kratochvíl 2007). The Archipelago counts more than twenty languages, mostly not previously documented. These languages, with exception of Alorese and Malay, have been argued to belong to the Trans New Guinea family (cf. Pawley 2001; Ross 2005). The affiliation and internal subgrouping are currently investigated (Holton, Klamer and Kratochvíl 2009). The map in Figure 1 gives an overview of the linguistic situation of the Alor Island.

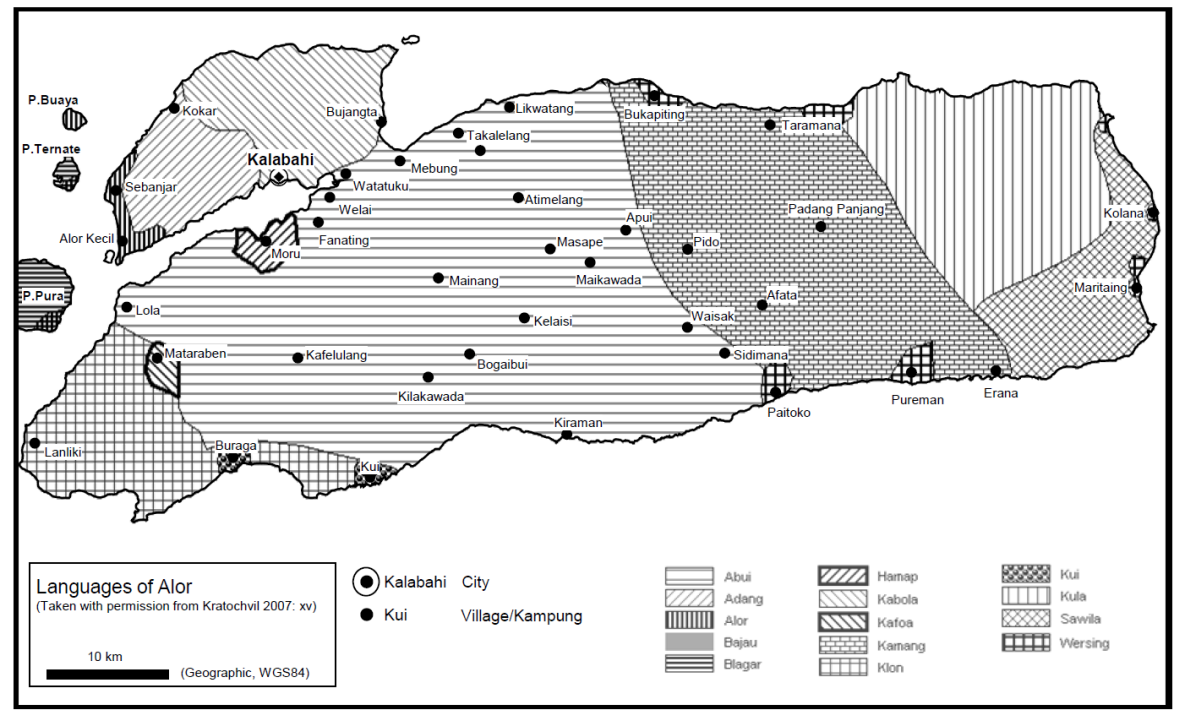

Figure 1. Linguistic situation in Alor Island 
This paper describes the structure and semantics of the complex verbs in Abui that consist of three generic verbs. In Section 3, we first describe the semantic contribution of the head of the derivation, the final generic verb. We will see that the general function of generic verbs in this position is to act as a kind of 'event classifier', encoding various types of semantic information about the type of event denoted by the complex verb. In Section 4, the semantic contribution of generic verbs in medial position is discussed, and we argue that these medial generic verbs are in fact overt expressions of the inner aspect ('Aktionsart') of the event. In Section 5, we discuss the semantic contribution of initial generic verbs, and show that they encode the 'locus' or spatial constellation of the event participants. In Section 6, we summarize the conclusions and point out some cross-linguistic parallels.

\section{Abui generic verbs}

Abui verbs belong to open or closed verb classes. One of the Abui closed verb classes are 'generic verbs' (GVs). Generic verbs are verbs with a non-specific, general semantics, whose interpretation is often contextually dependent. Abui has eighteen of such generic verbs. They are listed in Table 1 on the next page with their gloss and some illustrations of how they are interpreted in context. Although the glosses are used throughout this paper, it should be kept in mind that they are only crude approximations of the semantics of the generic verbs. In the discussion below we will see that their semantics is generally more abstract than their English glosses suggest. The semantic functions of the generic verbs as circumscribed in Tables 5 on page 215, 10 on page 221, and 14 on page 225 may serve to illustrate this point.

As can be seen from Table 1 on the next page, an Abui generic verb is very small - it consists of just one segment, a consonant or a vowel. In other words, generic verbs are mono-segmental roots. generic verbs $n g / n$, $t / s$, and $l / r$ are analyzed as alternating roots. Their alternation reflects the internal temporal structure of the referred event (AKTIONSART). They refer to the same event that is viewed either as having an endpoint (COMPLETIVE), or an initial point (INCEPTIVE).

In this paper we propose that some morphologically complex verbs in Abui are built up by combining generic verbs with each other, that is, the generic verbs in Table 1 on the facing page are used to derive verbal compounds. We consider various paradigms of verbs, and investigate the regu- 
Table 1. Abui generic verbs

\begin{tabular}{lll}
\hline ROOT & GLOSS & MEANING \\
\hline$b$ & JOIN & join, adjoin, absorb \\
$d$ & HOLD & hold, get, control \\
$f$ & SEVER & hide, loose, sever, lost, unknown \\
$h$ & LACK & elsewhere, out, not here, not exist \\
$k$ & THROW & throw, bring, receive, pass, feed on, move in \\
$l$ & GIVE & give, make, affect \\
$m$ & IN/TAKE & take, with, in \\
$n g$ & LOOK & look, face, turn to \\
$n$ & SEE & see, perceive, know \\
$p$ & TOUCH & touch, be near, approach \\
$r$ & REACH & reach, accomplish, given \\
$t$ & LIE & lie, on, touch surface \\
$s$ & LAY & set, move, displace \\
$i$ & PUT & put, lay down, stop \\
$u$ & LEAVE & leave, remote, demote, get away, gone \\
$a$ & AT & be at, exist, last \\
$e$ & MOVE & continue, add value \\
$o$ & POINT & point, limit \\
\hline
\end{tabular}

larities involved in their form and meaning. We argue that the form-meaning contrasts found in the paradigms discussed here are systematic.

While the morphological patterns described in this paper are systematic form-meaning relations, the system described here is neither productive, nor completely regular. In other words, Abui speakers do not coin new verbs by simply combining generic verbs, and not every verb discussed below has a meaning that is entirely predictable on the basis of its stipulated internal structure.

In our analysis, we take the conservative view that the segments of a verb can only be analyzed as morphemes when there is positive evidence to do so. A morphologically complex verb that is composed of generic verbs will only be identified as such under the strict condition that it occurs in a paradigm with other complex verbs, which shows a minimal contrast in form coupled to a systematic contrast in meaning. This is why the paradigms discussed in this paper are crucial. There are also many Abui verbs that do not show systematic form-meaning contrast with other verbs. It may be that such verbs are morphologically simple forms, but it may also be that some of them are de- 
rived forms whose semantics have shifted so much over time that we have no evidence of their former morphological composition. These verbs we therefore assume to be (synchronically) simplex forms.

Because an Abui phonological word minimally consists of one light syllable, only the vocalic generic verbs can be used as independent phonological words. An illustration is the verb $i$ 'put', which functions as the main predicate in (1a). Consonantal generic verbs must always have a phonological host: they either occur with a pronominal prefix, e. g. he- in (1b), or attach to other lexical items, as illustrated in (2). In these examples, the generic verbs $l$ 'give' and $n g$ 'look' derive complex verbs from a nominal base. In line with the head-final character of Abui morpho-syntax, where objects precede verbs and negations and conjunctions occur at the end of a clause, in verbs that are derived by a generic verb this generic verb is placed at the end of the complex. We gloss the generic verbs in small case when they function as a single main predicate. This is illustrated by $i$ 'put' in (1a) and $-l$ 'give' in (1b). In all other functions the same gloss is in small capitals, as in (2).

(1) a. di sura nu meja taha-ng $i-i$

$3 \mathrm{~A}$ book SPC table on=LOOK put-PFV

He put the book on the table.' [B07.034.06]

b. ama nu seng mi maama he-l

person SPC money take father 3II.LOC-give

'Someone gives money to the father', lit. 'someone takes money gives father'

(2) a. namu 'wound n.' > namu-l (wound-GIVE) 'wound v.'

b. bale 'bamboo sp.' > bale-ng (bamboo-LOOK) 'cook in bamboo tubes'

All morphologically derived verbs in Abui contain at least one generic verb. The final generic verb of a complex verb is considered the head of the derivation because it determines the meaning, category or valency of the derivation. The category-changing function was illustrated in $(2 a-2 b)$, where $l$ and $n g$ derive verbs from nouns. In Table 2 on the next page it is illustrated how the final generic verb determines the meaning and valency of the derived form. The generic verb $a$ 'at' derives stative intransitive verbs. The generic verbs $l$ and $n g$ derive verbs that may combine with one or two arguments.

Abui has two major types of complex verbs. One type combines a generic verb with a non-generic verb root form; in the other type, generic verbs are 
Table 2. Derivations from the stem ar

\begin{tabular}{lll}
\hline ROOT & GLOSS & MEANING \\
\hline$-a r$ & & 'burn' \\
$a r-a$ & (burn-AT) & 'be on fire' \\
$a r-a-l$ & (burn-AT-GIVE) & 'set on fire' \\
ar- $a-n g$ & (burn-AT-LOOK) & 'glow' \\
\hline
\end{tabular}

Table 3. Some heterogenous derivations

\begin{tabular}{|c|c|c|c|}
\hline & ROOT & GLOSS & MEANING \\
\hline \multirow[t]{3}{*}{ a. } & kaang & (good) & 'good, proper' \\
\hline & kaan-r- & (good.CPL-REACH) & 'make good, finish, ready' \\
\hline & kaang-d- & (good- $\underline{\text { HOLD }})$ & 'become good, ready' \\
\hline \multirow[t]{3}{*}{$\mathrm{b}$} & ahel & (breathe) & 'breathe, sniff' \\
\hline & ahel-r- & (breathe-REACH) & 'make tired, fatigue' \\
\hline & ahel-i & (breathe-PUT) & 'have a rest' \\
\hline & buka & (open) & ‘open’ (Malay) \\
\hline & buka-d- & (open- $\underline{\text { HOLD }}$ ) & 'open up' \\
\hline \multirow[t]{2}{*}{ d. } & kirek & (tearing.sound) & 'sound of tearing' \\
\hline & kirek-d- & (ONO-HOLD) & 'get torn' \\
\hline
\end{tabular}

combined with each other. We saw examples of the former type in (2) above, where the non-generic verb root is a noun. Other complex verbs of this type are listed in Table 3. The generic verb may combine with an open class verb, such as kaang 'good' or ahel 'breathe', a loan word, such as buka 'open', or an onomatopoeic root, such as kirek 'sound of tearing (cloth)'.

Complex verbs that contain a non-generic verb root, like those in example (2) or Table 3 will be called 'heterogeneous' complex verbs. They are contrasted with 'homogeneous' complex verbs, which consist of combinations of generic verbs only (cf. Kratochvíl 2007: 299-345). An illustrative paradigm of the latter is given in Table 4 on the following page. It is this type of complex verb that we are concerned with in the present paper. Although most of the derivations in Table 4 on the next page contain more than three generic verbs, the present paper will focus on derivations that consist of three generic verbs. The main reason for this is that paradigms with contrasting tripartite complex verbs occur most frequently and have the most transparent semantics.

It must be noted here that some logical combinations of generic verbs do not occur in tripartite derived verbs because they would not constitute a well- 
Table 4. Derivations sharing the stem $t u$ -

\begin{tabular}{lll}
\hline ROOT & GLOSS & MEANING \\
\hline$t-u-n g$ & LIE-LEAVE-LOOK & 'perforate, pierce' \\
$t-u-n-r-$ & LIE-LEAVE-SEE-REACH & 'make a hole, inject' \\
$t-u-l$ & LIE-LEAVE-GIVE & 'stick out, give out' \\
$t-u-k$ & LIE-LEAVE-THROW & 'stick out, measure' \\
$t-u-k-u$ & LIE-LEAVE-THROW-LEAVE & 'cut off' \\
$t-u-k-o-n g$ & LIE-LEAVE-THROW-POINT-LOOK & 'cut at something' \\
$t-u-k-o-l-$ & LIE-LEAVE-THROW-POINT-GIVE & 'cut in' \\
$t-u-k-o-l-r$ & LIE-LEAVE-THROW-POINT-GIVE-REACH & 'make a hole' \\
$t-u-k-o-l-a-d-$ & LIE-LEAVE-THROW-POINT-GIVE-AT-HOLD & 'leak, have a hole' \\
\hline
\end{tabular}

formed syllable or minimal word in Abui. For example, derivations with two initial consonantal generic verbs are not possible $(* p t a, * k p i$, or *lnu), nor are tripartite verbs combining two non-high vowel generic verbs (*tao, *koa, $* l o e$ ). This is because Abui syllable structure is strictly (consonant)-vowel(consonant), with only simple onsets and coda's, and coda's can consist of only consonants or high vowels.

\section{The semantic contribution of final generic verbs}

The final generic verb of a complex verb is the head of the derivation, as it determines the meaning, category and valence. Semantically, the final generic verb functions as a kind of 'event classifier', encoding various types of semantic information about the type of event expressed by the complex verb. These semantic dimensions include, for example, whether the event denoted by the verb is a state or a motion (and the orientation of the motion), whether the event involves causation (internal or external), or whether it is an achievement. Table 5 on the facing page presents a survey of the various event types that are marked by final generic verbs. Note that the meaning of the generic verb root and its function as event classifier are semantically connected, though the link is quite abstract. In the remainder of this section, we illustrate some of these event types encoded by the third generic verbs using paradigms of complex verbs that only contrast in their final generic verb.

Not all of the generic verbs in Table 5 on the next page are equally productive as event classifiers. For example, in the tripartite derivations that are the topic of this paper, the verbs $h, k, l, r, n g, n, p, t$, and $i$ frequently occur 
Table 5. Description of the event type marked by the generic verb in final position

\begin{tabular}{lll}
\hline ROOT & GLOSS & EVENT TYPE \\
\hline$b$ & JOIN & impact \\
$d$ & HOLD & internally caused change of state \\
$f$ & SEVER & separation \\
$h$ & LACK & perfect \\
$k$ & THROW & motion away from the deictic centre \\
$l$ & GIVE & externally caused change of state \\
$m$ & IN/TAKE & position in the deictic centre \\
$n g$ & LOOK & orientation towards deictic centre \\
$n$ & SEE & completed orientation towards deictic centre \\
$p$ & TOUCH & contact \\
$r$ & REACH & completed externally caused change \\
$t$ & LIE & completed horizontal contact, position \\
$s$ & LAY & horizontal orientation \\
$i$ & PUT & downwards motion, accomplishment \\
$u$ & LEAVE & perfect \\
$a$ & AT & state, position \\
$e$ & MOVE & ongoing motion \\
\hline
\end{tabular}

as final generic verbs. The verbs $l, r, d, n g$ and $i$ are typically used as final generic verb in larger derivations or in heterogeneous verbs. The verbs $f$ and $b$ have an overall low frequency. The verb $u$ is used most often in non-final position, or as the second generic verb in a bipartite derivation. The verbs $s$ and $m$ are typically used as initial generic verbs in verbs consisting of multiple generic verbs.

In Table 6, a paradigm is given where tripartite complex are derived from the base verb $t$ - $a$ 'be on'. We will discuss each of these derivations in detail below.

Table 6. Derivations sharing the stem $t a$ -

\begin{tabular}{lll}
\hline ROOT & GLOSS & MEANING \\
\hline$t-a$ & LIE-AT & 'be on, lie on' \\
$t-a-k$ & LIE-AT-THROW & 'shoot down, cover, bring on, plant' \\
$t-a-l$ & LIE-AT-GIVE & 'drop on' \\
$t-a-i$ & LIE-AT-PUT & 'put on' \\
$t-a-n g$ & LIE-AT-LOOK & 'release, let drop' \\
\hline
\end{tabular}


In $t$ - $a$ - $k$, the verb $k$ 'throw' derives a verb indicating a motion event, which causes the participant(s) to 'throw or move' an object to be lying down. Depending on the context in which the verb is used, it may get various interpretations, including 'to shoot', or 'to cover with'. An illustration is (3), where $t$ - $a$ - $k$ refers to shooting down birds.

(3) Arjun de-kartipel ong ba mara kuya ha-t-a-k name 3I.AL-catapult make SIM go.up.CNT bird 3II.PAT-LIE-AT-THROW

'Arjun made himself a catapult and went up shoot the birds.' [B06.014.03]

In (4), $t-a-k$ refers to covering one's head with a piece of cloth, 'to cover with' thus being a possible interpretation of 'move to lie on'.

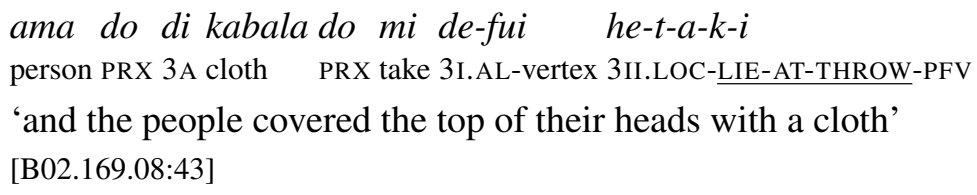

The final generic verb $l$ 'give' encodes an event that is externally caused and involves a transfer of participants. In the derivation $t$ - $a$ - $l$ this renders the interpretation of 'to drop on'. This is illustrated in (5). In (5a), the verb $t$ - $a$ - $l$ refers to the 'sowing' of tobacco seeds, in (5b), it refers to the 'dropping' of tears.
a. maama di kafaak ha-t-a-l
father 3A tobacco 3II.PAT-LIE-AT-GIVE

'Father sows the tobacco.' [B08.051.02]
b. t-ieng nai $t$-a-l-i ayok-ayok-d-a
DISTR.INAL-eye tear LIE-AT-GIVE-PFV RED[two]-HOLD-DUR

'Our eyes were dropping tears (each of us was crying).' [B08.050.11]

In final position, the generic verb $i$ 'put' derives a complex verb that refers to an achieved state or accomplished event. In $t-a-i$, the verb $i$ 'put' denotes a state of being put down or being put in a certain location. This is illustrated in (6). In (6a), $t-a-i$ is interpreted as 'to put st. down', in (6b), it refers to curing a person by 'putting on' medicine, while in (6c), it is used to express an order as something (a duty) that the old woman 'imposes on' the child.
a. na yambuk mi t-a-i natia
1s glass take LIE-AT-PUT stand.CNT
'I put down the glass.' [B04.053.01] 
b. ama he-l t-a-i tung ayok-d-a

person 3II.LOC-GIVE LIE-AT-PUT year two-HOLD-DUR

'People were treating him for two years.' [B07.022.04]

c. kalieta mayol do di moku do ho-t-a-i

old.person woman PRX 3A kid PRX 3II.REC-LIE-AT-PUT

'the old woman, she ordered the child' [B02.017.09:35]

In final position, the generic verb $n g$ 'look' classifies events as motions towards a location. Sometimes the verbs ending in $n g$ functions alike to applicative verbs in other languages. In (7), the verb $t$ - $a-n g$ is thus interpreted as 'to release (dogs)', as Abui hunting is typically done by setting dogs off to track down the prey.

(7) neng loku ba he-n-u kaai ha-t-a-ng kaang
man PL TOP 3II.LOC-like.PRX-PRF dog 3II.PAT-LIE-AT-LOOK good

'As for the men, these hunt.' [B07.032.06]

$\mathrm{Ng}$ 'look' encodes motions towards a location as well as low involvement of the actor. For example, $t-a-n g$ can contrast with $t$ - $a$ - $l$ 'to drop something', discussed in (5), when it is interpreted as 'let drop', for example, 'let water drop (on the floor)'.

Some more complex verbs with final generic verbs $k$ 'throw', $i$ 'put', $l$ 'give', and $n g$ 'look' are given in Table 7 on the next page. As was noted in Section 2, the derivational patterns shown by the paradigms are not always regular, and combinations that are logically possible are not always attested. Note also that $i$ 'put' refers to some aspectual dimension, but how this semantic contribution relates to the verbal root meaning 'put' is much less clear than in the case of $k$ 'throw', $l$ 'give', and $n g$ 'look'.

Now consider the paradigms in Table 8 on page 219. The verbs in the first column end in $k$ 'throw' and thus express a motion event. In contrast, the verbs $t$ 'lie' and $p$ 'touch' both express a non-motion event: a horizontal state, or a state of contact. As such, they mark 'states' (achievements, results) in contrast to the motions encoded by $k$. Further, $t$ and $p$ contrast in the position of the event participants: $t$ 'lie' refers to participant(s) in horizontal position, and $p$ 'touch' refers to participant(s) in contact with another object. Again, the derivational pattern observed in the paradigms here is not totally regular.

The final two sets of examples in Table 8 on page 219 illustrate the contrast in participant positions most clearly. Example (8) illustrates the uses of the forms $t-e-k$ and $t-e-t$. In (8a), the verb $t-e-k$ refers to a motion event that 
Table 7. Complex verbs with a contrasting final generic verb $k, l, n g$, and $i$

\begin{tabular}{|c|c|c|c|c|}
\hline & THROW & GIVE & LOOK & PUT \\
\hline \multirow[t]{2}{*}{ a. } & $d-a-k$ & $d-a-l$ & & $d-a-i$ \\
\hline & $\begin{array}{l}\text { HOLD-AT-THROW } \\
\text { 'cover' }\end{array}$ & $\begin{array}{l}\text { HOLD-AT-GIVE } \\
\text { 'handle, grab' }\end{array}$ & & $\begin{array}{l}\text { HOLD-AT-PUT } \\
\text { 'cram(med)' }\end{array}$ \\
\hline \multirow[t]{2}{*}{ b. } & $l-e-k$ & $l-e-l$ & & $l-e-i$ \\
\hline & $\begin{array}{l}\text { GIVE-MOVE-THROW } \\
\text { 'point to' }\end{array}$ & $\begin{array}{l}\text { GIVE-MOVE-GIVE } \\
\text { 'threaten, almost do' }\end{array}$ & & $\begin{array}{l}\text { GIVE-MOVE-PUT } \\
\text { 'miss (not hit)' }\end{array}$ \\
\hline \multirow[t]{2}{*}{ c. } & $t-u-k$ & $t-u-l$ & $t-u-n g$ & \\
\hline & $\begin{array}{l}\text { LIE-LEAVE-THROW } \\
\text { 'stick out, measure' }\end{array}$ & $\begin{array}{l}\text { LIE-LEAVE-GIVE } \\
\text { 'stick into' }\end{array}$ & $\begin{array}{l}\text { LIE-LEAVE-LOOK } \\
\text { 'perforate, pierce' }\end{array}$ & \\
\hline \multirow[t]{4}{*}{ d. } & $l-u-k$ & & $l-u-n g$ & \\
\hline & GIVE-LEAVE-THROW & & GIVE-LEAVE-LOOK & \\
\hline & 'rub, wipe, bend' & & 'be long-termed' & \\
\hline & motion & caused event & oriented to location & accomplished \\
\hline
\end{tabular}

leads to horizontal position. In a context where 'garden' is the object, the interpretation is that weeds are going to be cut down, or stepped on and broken, so that they end up on the ground. In (8b), the verb $t$ - $e$ - $t$ refers to a wall that collapsed during an earthquake. The final generic verb $t$ 'lie' indicates the final horizontal position of the wall has been reached. Tet is the final verb of the sentence and has to be inflected for aspect, in this case with the perfective suffix $-i$.

a. na yaa ne-'ut t-e-k

1s go 1S.AL-garden LIE-MOVE-THROW

'I go weed my gardens',

lit.: 'I go bring down my gardens.' [B01.035.32]

b. amakaang nuku kota ho-t-e-t-i

person one wall 3II.REC-LIE-MOVE-LIE-PFV

'the wall collapsed down on one person' [B05.078.01]

Example (9) shows the contrast between $k-e-k$ and $k$-e-t. The verb $k$-e- $k$ expresses a vertical motion towards the object, the blossom of a banana tree; in this context it is translated as 'to prod', that is, use a stick to prod at a banana blossom hanging in a tree. In (9b), the event $k$-e- $t$ involves a horizontal movement that has reached its final boundary. 
Table 8. Complex verbs with a contrasting final generic verb $k, l, n g$, and $i$

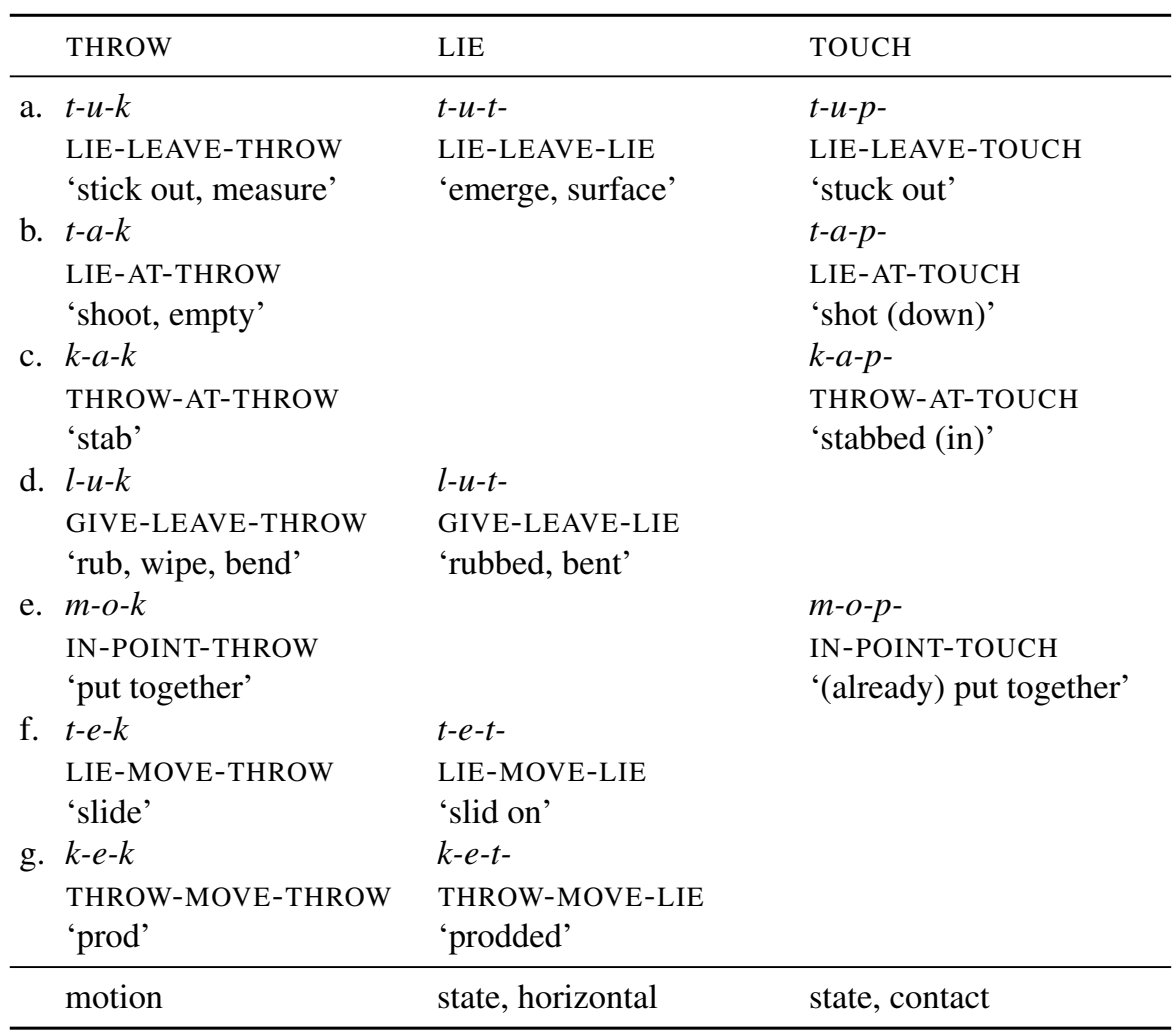

a. di baleei wataka do k-e-k he-we 3A banana blossom PRX THROW-MOVE-THROW 3II.LOC-leave 'she went to prod at the banana blossom' [B02.027.03:59]

b. na wi ha-k-o-k-u nemang tahai maar 1s stone 3II.PAT-THROW-POINT-THROW-PRF shells search cook.CPL kaan-r-i, he-k-e-t ba nee GOOD-REACH-PFV 3II.LOC-THROW-MOVE-LIE SIM eat 'I prodded the stones, searched for shells, cooked them, poked them out and ate them.' [B05.070.02]

As the final example in this section, consider the paradigm derived from $l$-oin Table 9 on the following page. If the semantics of these derivation reflected their morphological make-up in a regular way, the complex verb ending in $k$ 'throw' would refer to a motion event, a final $i$ 'put' would mark an accom- 
plishment, with $h$ 'lack' the verb would have perfect aspect, and $n g$ 'look' would mark orientation towards a location. As it is, it is very hard to find these semantics reflected in the translations as given.

Table 9. Possible paradigm derived from l-o-

\begin{tabular}{llll}
\hline THROW & PUT & LACK & LOOK \\
\hline$l$-o- $k$ & $l$-o- $i$ & $l$-o- $h$ - & $l$-o-ng \\
GIVE-POINT-THROW & GIVE-POINT-PUT & GIVE-POINT-LACK & GIVE-POINT-LOOK \\
'prick, push' & 'to chase, distance' & 'distant, long' & 'long' \\
\hline
\end{tabular}

While the different verb forms in Table 9 show some semantic overlap, it is impossible to analyse all of them as regularly derived compounds; the semantic contribution of their head (the final generic verb) is elusive. It is difficult to relate it to how it is used in other paradigms. In other words, the overall morphological function of particular generic verbs can only be spotted by comparing their function across various sets of paradigms (cf. the sets discussed above, and the ones to be discussed in the sections below). But even then, the patterns are not always regular and semantically transparent, and there are many paradigms with lexical gaps.

The unpredictable, lexicalised nature of the derivations discussed here is due to the nature of the generic verbs involved. The complex verbs are build from generic verbs, and such verbs already start out with a rather abstract (or vague) lexical semantic content. Combining with each other to form new verbal compounds, they become reanalyzed as bound morphemes and lose some of their verbal semantics (which was already underspecified to begin with). Abstract verbs interacting with other abstract verbs in a derivation are also bound to undergo semantic drift or shift, with the result that the compound may become reanalyzed as a simplex word over time. Cross-linguistically, the lexicalization and subsequent semantic drift of compounds, as well as the existence of paradigmatic gaps is characteristic of all types of compounding (Spencer 1991: 312). This is because the meaning contribution of compound structure generally involves a high degree of abstractness or vagueness, since the semantic relation between the elements in a compound is not formally expressed (cf. Booij 2005: 210).

Despite these complications, however, we have argued that there is evidence to analyze the final generic verbs in complex verbs as 'event classi- 
fiers' that encode information about the type of event denoted by the verb. Interestingly, their function as final verb differs from the function they have when they occur as non-heads, i. e. in medial or initial position. This will be discussed in the next two sections.

\section{The semantic contribution of medial generic verbs}

For the phonological reasons set out in Section 1, a tripartite complex verb will always have a vocalic generic verb in medial position. The vocalic generic verbs are $a$ 'at', $i$ 'put', $e$ 'move', $o$ 'point', and $u$ 'leave'. In medial position, these verbs encode the inner aspect (Aktionsart) of the event, providing information on its boundedness.

Table 10. The aspectual function of vocalic generic verbs in medial position

\begin{tabular}{llll}
\hline generic verb & GLOSS & type & boundary \\
\hline$i$ & PUT & terminative & bounded at end \\
$u$ & LEAVE & perfect & beyond final boundary \\
$a$ & AT & progressive & no boundary \\
$e$ & MOVE & ingressive & bounded at start \\
$o$ & POINT & punctual & bounded at start and end \\
\hline
\end{tabular}

In Table 10, we list the vocalic generic verbs with the aspectual function they have in medial position. The verb $a$ 'at' encodes an unbounded event or state ('progressive'), the verb $o$ 'point' encodes an event that is bounded at both start and end ('punctual'), the verb $i$ 'put' encodes events that are bounded at the end ('terminative'), and it contrasts with the verb $e$ 'move' that encodes events which are bounded only at the start ('ingressive'). Finally, the verb $u$ 'leave' encodes events, which have reached beyond their final boundary ('perfect'). In Table 11 on the next page some paradigms illustrating the contrast are given. The last column of verbs in Table 11 is exmplified in (10)-(16). In (10), the verb $t-a-k$ refers to shooting down of a pig. The root $a$ 'at' in the complex verb $t-a-k$ refers to the Aktionsart of 'lying' and indicates that the event of 'lying' has no internal boundary. The final verb $k$ classifies this verb as a motion event that brings about the result that a pig is 'lying down'; the actor does not directly affect the undergoer, and the resulting event of lying has no boundary. The undergoer participant 'pig' is ex- 
Table 11. Derivations with contrasting generic verbs in medial position

\begin{tabular}{|c|c|c|c|}
\hline $\begin{array}{l}a(\mathrm{AT}) \\
\text { progressive }\end{array}$ & $\begin{array}{l}l-a-k \\
\text { GIVE-AT-THROW } \\
\text { 'mark, count' }\end{array}$ & $\begin{array}{l}k-a-k \\
\text { THROW-AT-THROW } \\
\text { 'penetrate, stab' }\end{array}$ & $\begin{array}{l}t-a-k \\
\text { LIE-AT-THROW } \\
\text { 'put down, shoot' }\end{array}$ \\
\hline $\begin{array}{l}o(\text { POINT }) \\
\text { punctual }\end{array}$ & $\begin{array}{l}l-o-k \\
\text { GIVE-POINT-THROW } \\
\text { 'prick' }\end{array}$ & $\begin{array}{l}k-o-k \\
\text { THROW-POINT-THROW } \\
\text { 'prod (once)' }\end{array}$ & $\begin{array}{l}t \text { - } o-k \\
\text { LIE-POINT-THROW } \\
\text { 'drop, pour' }\end{array}$ \\
\hline $\begin{array}{l}i \text { (PUT) } \\
\text { terminative }\end{array}$ & $\begin{array}{l}l-i-k \\
\text { GIVE-PUT-THROW } \\
\text { 'bend' }\end{array}$ & $\begin{array}{l}k-i-k \\
\text { THROW-PUT-THROW } \\
\text { 'sweep' }\end{array}$ & $\begin{array}{l}t-i-k \\
\text { LIE-PUT-THROW } \\
\text { 'loosen, untie' }\end{array}$ \\
\hline $\begin{array}{l}e \text { (MOVE) } \\
\text { ingressive }\end{array}$ & $\begin{array}{l}l-e-k \\
\text { GIVE-MOVE-THROW } \\
\text { 'point to/ at' }\end{array}$ & $\begin{array}{l}k-e-k \\
\text { THROW-MOVE-THROW } \\
\text { 'prod' }\end{array}$ & $\begin{array}{l}t-e-k \\
\text { LIE-MOVE-THROW } \\
\text { 'slide' }\end{array}$ \\
\hline $\begin{array}{l}u \text { (LEAVE) } \\
\text { perfect }\end{array}$ & $\begin{array}{l}l-u-k \\
\text { GIVE-LEAVE-THROW } \\
\text { 'rub, bend' }\end{array}$ & $\begin{array}{l}k-u-k \\
\text { THROW-LEAVE-THROW } \\
\text { 'push out' }\end{array}$ & $\begin{array}{l}t-u-k \\
\text { LIE-LEAVE-THROW } \\
\text { 'stick' }\end{array}$ \\
\hline
\end{tabular}

pressed with the NP fe nu 'a pig' and co-indexed as patient with the prefix ha-.

(10) no-buoka ba pulang mi fe nu ha-t-a-k

1S.REC-far SIM arrow take pig SPC 3II.PAT-LIE-AT-THROW

From far, I shoot a pig with an arrow.' [B05.067.01]

In contrast, the verb $t-o-k$ in (11) refers to 'pouring' or 'dropping' water on the fire. Here the generic verb $o$ 'point' encodes that this event is punctual: it has a limited time span and occurs once.

na ya mi ba ara he-t-o-k

$1 \mathrm{~s}$ water take SIM fire 3II.LOC-LIE-POINT-THROW

'I pour water on the fire.' [B10.021.13]

In (12), the verb $t$-o- $k$ is interpreted as 'demolish' or 'break down', an event with a limited time span. The verb $k$ marks it as a motion away from the speaker. Note also that the undergoer must be expressed with the patient prefix $h a$-indicating a significant affectedness and change of state.

(12) na fala ha-t-o-k

1s house 3II.PAT-LIE-POINT-THROW

'I demolish the house.' [B03.002.03] 
In (13), the complex verb $t-e-k$ also ends in $k$ and refers to a motion event, which now originates from where the wall once stood. The verb $e$ encodes an event of 'sliding down, collapsing' that has just started. In other words, an event with an initial boundary.

(13) kota no-t-e-k-e

wall 1S.REC-LIE-MOVE-THROW-IPFV

'the wall slides down on me' [B05.078.01]

The inner aspect of the event $t-e-k$ contrasts with that of $t-i-k$, as the latter has a final boundary. An example is given in (14), where a child that was locked up (the door is tied up with a rope), managed to untie the door and get out to play. The actual untying is encoded as a motion (encoded by final $k$ ) that brings about a final boundary (encoded by $i$ ) to 'lying'. The single participant is expressed with two arguments. The free pronoun di marking the actor records the argument of the verb $t-i-k$. The coreferential prefix $d e-$ records the same participant as the benefactive of the auxiliary verb $l$ 'give'.

'He released himself and played.' [B10.023.03]

The verb $t-u$ - $k$ covers a range of meanings including 'measure, emerge, stick out'. In (15), it combines with two arguments, a third person actor $d i$ and a first person undergoer no-. $T-u-k$ refers to the event of 'measuring clothes' which is described as clothes that are laid down in a motion away from the actor.

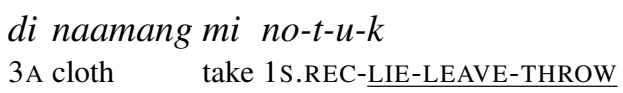

'He measured me the clothes on.' [B10.021.06]

In (16), $t-u-k$ refers to knowing a person, an interpretation that is related to 'measure' in example (15) above.

$$
\begin{aligned}
& \text { di dara } n a-t-u-k \quad \text { naha to } \\
& \text { 3A still 1S.PAT-LIE-LEAVE-THROW not PRX.AD } \\
& \text { 'He does not know me yet.' [B10.021.04] }
\end{aligned}
$$

Some additional (partial) paradigms are given in Table 12 on the following page. The vocalic generic verbs encode the internal temporal structure of the encoded events. In sum, in verb lexemes consisting of three segments, the 
Table 12. Derivations with contrasting generic verbs in medial position

\begin{tabular}{|c|c|c|c|}
\hline $\begin{array}{l}a(\mathrm{AT}) \\
\text { progressive }\end{array}$ & $\begin{array}{l}w-a-k \\
\text { LEAVE-AT-THROW } \\
\text { 'embrace, throw' }\end{array}$ & & $\begin{array}{l}s-a-k \\
\text { LAY-AT-THROW } \\
\text { 'place along' }\end{array}$ \\
\hline $\begin{array}{l}o(\text { POINT }) \\
\text { punctual }\end{array}$ & $\begin{array}{l}w \text { - } o \text { - } k \\
\text { LEAVE-POINT-THROW } \\
\text { 'throw (once)' }\end{array}$ & $\begin{array}{l}k-o-l \\
\text { THROW-POINT-GIVE } \\
\text { 'tie, bind' }\end{array}$ & $\begin{array}{l}s-o-k \\
\text { LAY-POINT-THROW } \\
\text { 'pass along' }\end{array}$ \\
\hline $\begin{array}{l}i(\mathrm{PUT}) \\
\text { terminative }\end{array}$ & $\begin{array}{l}w-i-k \\
\text { LEAVE-PUT-THROW } \\
\text { 'carry away' }\end{array}$ & $\begin{array}{l}k-i-l \\
\text { THROW-PUT-GIVE } \\
\text { 'turn over' }\end{array}$ & $\begin{array}{l}s-i-k \\
\text { LAY-PUT-THROW } \\
\text { 'break off, pluck' }\end{array}$ \\
\hline $\begin{array}{l}u \text { (LEAVE) } \\
\text { perfect }\end{array}$ & & $\begin{array}{l}k \text { - } u \text { - } l \\
\text { THROW-LEAVE-GIVE } \\
\text { 'throw(n)' }\end{array}$ & \\
\hline
\end{tabular}

medial vocalic generic verbs encodes the inner aspect of the event denoted by the verb. Abui thus has a set of complex verbs that express aktionsart systematically and overtly in their derivational morphology.

\section{The semantic contribution of initial generic verbs}

In this section, we analyse the function of the initial generic verb in a complex verb as describing something we refer to as the 'locus' of the event, or the spatial constellation of the event. Consider now the derivations in Table 13. Because of their final verb $k$, all these verbs refer to events that are classified as motions, while the medial verb $a$ 'at' indicates that the event has no internal boundary. The initial verb is variable, and indicates the spatial constellation of the event.

Table 13. Derivations with contrasting generic verbs in initial position

\begin{tabular}{llll}
\hline$t-a-k$ & $s-a-k$ & $p-a-k$ & $d-a-k$ \\
LIE-AT-THROW & LAY-AT-THROW & TOUCH-AT-THROW & HOLD-AT-THROW \\
'shoot, put down' & 'place along' & 'dump, crash in' & 'clutch, trap' \\
$b-a-k$ & $f-a-k$ & $l-a-k$ & $w$ - $a$ - $k$ \\
JOIN-AT-THROW & SEVER-AT-THROW & GIVE-AT-THROW & LEAVE-AT-THROW \\
'swallow, snatch' & 'break' & 'mark, count' & 'embrace, throw' \\
\hline
\end{tabular}


Table 14. Event 'locus' encoded by the initial generic verb

\begin{tabular}{lll}
\hline GENERIC VERB & GLOSS & 'EVENT LOCUS' \\
\hline$b$ & JOIN & Intersecting locus \\
$d$ & HOLD & Overall contact \\
$f$ & SEVER & Separation \\
$h$ & LACK & $?$ \\
$k$ & THROW & Out-of-reach locus \\
$l$ & GIVE & Within-reach locus \\
$m$ & IN/TAKE & In-deictic-centre locus \\
$n$ & SEE & ?Visible locus \\
$n g$ & LOOK & $*$ \\
$p$ & TOUCH & Contact locus \\
$r$ & REACH & Within-reach locus \\
$s$ & LAY & Parallel locus \\
$t$ & LIE & Horizontal locus \\
$i / y$ & PUT & $*$ \\
$u / w$ & LEAVE & Remote locus \\
\hline
\end{tabular}

As 'locus' marking derivational morphemes, initial generic verbs take a perspective that is quite different from what we are used to in derivational morphology. For example, the verb $t$ 'lie' indicates a horizontal 'locus' that is reached by the motion (expressed by $k$ ). The verb $s$ 'lay' indicates a parallel 'locus'. The verb $p$ 'touch' indicates a locus that may be described as 'touching of a surface', while the root $d$ 'hold' encodes that the event involves an 'overall' type of contact between participants and their location. The root $b$ 'join' indicates an intersecting locus, while the root $f$ 'sever' refers to a separated locus. The root $l$ 'give' refers to a locus that may be described as 'in reach'. Practically it means that the involved participants are 'within reach' of each other, but more distant from each other than e. g. when the generic verb is $p$ 'touch' or $b$ 'join'. At the same time the participants are still within reach of each other, unlike the participants in cases when the roots $u$ 'leave' (pronounced and written as $w$ in initial position) and $f$ 'sever' are used. The verb $u$ 'leave' indicates the remote locus. A summary is given in Table 14 . (Question marks indicate functions that are unclear to us, asterisks indicate unattested derivations.)

The verb $s$ - $a$ - $k$ describes the event of motion that brings about "parallel lying'. In (17a), it refers to the parallel arrangement of bamboo. In (17b), it refers to making an appointment, where the agreement is perhaps considered 
as some kind of 'parallel arrangement' of suggestions/ideas in the vicinity of the speaker.

a. ri ri-mai $s$-a-k he-te-l tahi- $i$

2P 2P.AL-bamboo LAY-AT-THROW 3II.LOC-DISTR.LOC-GIVE ON.CPL-PFV

'you put bamboo in parallel, put it together on top of each other' [B02.004.05:20]

b. ama el na-pe-i $s-a-k-i$

person before 1s.PAT-near-PFV LAY-AT-THROW-PFV

'people made an appointment with me' [B02.074.08:16]

In (18), the verb $p$-a-k refers to car passengers crashing down into a ravine. It is a motion event (encoded by $k$ ), and the initial generic verb $p$ 'touch' encodes the 'contact locus' of the event, the contact between the participants and some location. The motion is oriented downward.

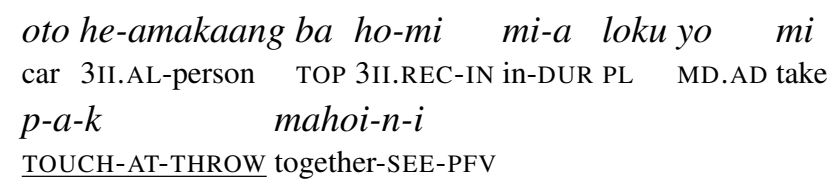

'the car passengers that were in the car, they crashed (into a ravine) all together' [B05.071.05]

In (19a), $d$-a-k refers to holding someone tight. The initial root $d$ 'hold' indicates that the type of contact between the participants involves the entire surface, i. e. is 'overall'. In (19b), $d-a-k$ refers to leaves applied in traditional healing that are 'clutched' on to the speaker. The verb $d-a-k$ is also used to refer to the clutching of fish and mice in bamboo traps.

a. me na-d-a-k-e! come 1s.pat-HOLD-AT-THROW-IPFV

'Come and hold me tight!' [B10.019.05]

b. tuli tala mi ba ne-l ha-d-a-k-e tree.sp. leaves take SIM 1s.LOC-GIVE 3II.PAT-HOLD-AT-THROW-IPFV

'Take the leaves of the tuli tree and clutch them on me.' [B10.021.01]

In (20), $b$ - $a$ - $k$ indicates a motion event with 'intersecting locus'. It can be interpreted as 'snatch', where one participant intersects the location of another. It can also refer to 'jaws', 'biting' or 'snatching food'.

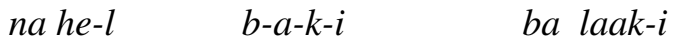

1s 3II.LOC-GIVE JOIN-AT-THROW-PFV SIM leave.for-PFV 
'I snatched him away.' [B10.024.05]

In (21a), the verb $f$-a-k is used. Here, the motion has a 'separation locus', and the verb is interpreted as 'break': in a leg that breaks, parts are separated from each other. In (21b), the same verb is used in a transitive construction referring to breaking a banana.

\section{a. abui mi-a ne-toku $f-a-k-i$ \\ mountain in-DUR 1s.AL-leg SEVER-AT-THROW-PFV}

'my leg broke in the mountains' [B06.017.07]

b. $p i=f a l$ baleei $f$ - $a-k$

$1 \mathrm{PI}=$ together banana SEVER-AT-THROW

'We share a banana, lit. we break a banana together.' [B10.007.01]

In (22a), the verb $l-a-k$ refers to a motion away from the actor and affecting a house that is 'in-reach locus' with respect of the actor. Its meaning corresponds to the English verb 'demolish' or 'take apart'. In (22b), the same verb refers to the event of 'marking' or 'recognizing'. In a serial construction with iéng 'look', $l-a-k$ refers to 'knowing someone'.

a. maama di fala ha-l-a-k

father 3A house 3II.PAT-GIVE-AT-THROW

'Father demolished the house.' [B06.011.02]

b. nahe-do n-iéng l-a-k naha

1s 3II.LOC-HOLD.PNCT 1s.PAT-look GIVE-AT-THROW not

'I don't know him' [B10.047.11]

In (23a), w-a-t refers to a motion with 'remote locus'. The verb refers to 'abandoning' of parents by their children. In (23b) $w$ - $a-k$ refers to the 'embracing' of two participants, which is encoded as a motion, with $w$ 'leave' indicating the remote locus. The distributive prefix $t a$ - is used to encode the reciprocal involvement of the participants.

a. ni-ya maama $o$ w-a-t he!

1PE.AL-mother father MD LEAVE-AT-LIE PROH

'we should not abandon our mother and father' [B02.158.00:02]

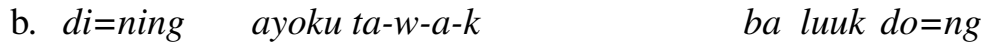

$3 \mathrm{~A}=$ in.number two DISTR.PAT-LEAVE-AT-THROW SIM dance PRX=LOOK

we

leave

'they both embraced (each other) to enter the dance' [B02.087.08:17] 
Table 15. Partial derivations with contrasting generic verbs in initial position

\begin{tabular}{llll}
\hline$p$ - $a$ - $n g$ & $m$ - $a$ - $n g$ & $t$ - $a$ - $n g$ & $b$ - $a$ - $n g$ \\
TOUCH-AT-LOOK & IN-AT-LOOK & LIE-AT-LOOK & JOIN-AT-LOOK \\
'feel, perceive' & 'possess' & 'release' & 'carry on shoulder' \\
$f-u-l$ & $k$ - $u$ - $l$ & $t$ - $u$ - $l$ & $r$ - $u$ - $l$ \\
SEVER-LEAVE-GIVE & THROW-LEAVE-GIVE & LIE-LEAVE-GIVE & REACH-LEAVE-GIVE \\
'swallow' & 'throw' & 'stick out, measure' 'loosen, let slide' \\
\hline
\end{tabular}

Table 15 lists two paradigms of complex verbs with an alternating initial generic verb. In the first row, the verbs end in $n g$, which encodes that the event is oriented towards a location. The verb $p$ encodes 'contact' between the participants, $m$ encodes that the participants are at the same location, $t$ encodes that they are in horizontal position, and $b$ encodes that the participant(s) have impact on something else. In the second row, the verbs end in $l$ 'give' which encodes that the event is externally caused. The medial verb $u$ 'leave' encodes that the event has reached its final boundary and has persistent effect. The initial verbs encode the event locus: $f$ 'sever' refers to the separation locus of two participants, $k$ 'throw' refers to locus that is not within reach (but not too remote either), $t$ 'lie' refers to the horizontal locus of the participants, and $r$ 'reach' refers to the locus where participants were previously 'in reach' of each other.

In sum, we have argued that when a generic verb occurs in the initial position of a tripartite complex verb, it describes the 'event locus'; that is the spatial constellation of the event participants.

\section{Conclusions and cross-linguistic perspective}

Abui complex verbs behave as single morpho-syntactic units. Heterogeneous complex verbs consist of a non-generic root and a generic verb (generic verb). Homogeneous complex verbs are composed of only generic verbs. In this paper, we have analyzed a number of Abui verbs as homogeneous complex verbs that combine three generic verbs to derive verbal compounds. The semantic composition of such tripartite compounds can be schematically represented as in (24). 
The final generic verb of these compounds is the morphological head and encodes the event type. The medial and initial generic verbs are the dependent or modifying elements. In medial position, the generic verb is a vowel and encodes the telic properties of the event (inner aspect). generic verbs in initial position describe the 'event locus'. For many of the generic verbs we can observe that the different functions attached to the same phoneme in initial, medial and final position are semantically related.

When our Abui consultants translate the meaning of a complex verb, unable to find a fitting Malay equivalent, they regularly resort to hand gestures that express the locus and indicate the trajectory of the event (for instance the verb $d$ 'hold' is illustrated by putting one hand on top of an object or on a table, the verb $t$ 'lie' is illustrated by putting both hands on each other. Systematic research into this use of gesture could provide additional insights in the type of event decompositions suggested in this paper.

Abui complex predicates have parallels in constructions found in other languages. A closed set of inflecting verbs with a classificatory function is a common feature in some Northern Australian languages (Schultze-Berndt 2000; McGregor 2002). Classificatory verbs are also found in the some TransNew-Guinea highland languages of the Papua mainland, combining with nominals and stative verbs (Lang 1975). In Kalam and Kobon (Davies 1984; Pawley 1987, 1991, 2004, 2005), classificatory verbs can combine with each other in a similar way as the complex predicates in Abui. As stated in Section 1, claims have been made that the highland languages might be related with the non-Austronesian languages of Alor and Pantar Archipelago.

The Kalam verb inventory is smallish, about 100 verbs, and about 25 of these are used frequently. As in Abui, the Kalam verbs have very generic meanings that do not correspond to the meanings of single verbs in more familiar languages like English. (It is thus unfortunate that English must be used for the glossing of such generic verbs.) The Kalam generic verbs often combine with each other. However, in the Kalam system, a root verb may only occur once in a verb sequence, while we have seen that in Abui, the same generic verb can occur more than once in one and the same derivation. Kalam and Kobon verb complexes have been analyzed as serial verb constructions. Consider now the Kalam example in Table 16 on the next page. The data come from Pawley $(1969,2005)$ and from Pawley and Lane (1998).

The verb ag 'say' occurs as either the first or the second member of the complex verb. As the second verb it appears to have a classifying function: it refers to the type of the event. As a first verb, it specifies the event and encodes 
Table 16. Kalam complex verbs derived from ag 'say'

\begin{tabular}{lll}
\hline VERB & GLOSS & MEANING \\
\hline ag $l$ - & SAY STABILIZE & 'ask to remain, make an appointment' \\
ag $\tilde{n}$ - & SAY TRANSFER & 'tell, inform' \\
ag $t$ - & SAY SEVER & 'interrupt' \\
ag $n$ n- & SAY PERCEIVE & 'request, ask, inquire' \\
ag weg- & SAY HIDE & 'tell secretly' \\
ag ask- & SAY AVOID & 'reject, refuse' \\
ag ay- & SAY PUT & 'ask s.o. to remain, make an appointment' \\
yn ag- & SEE & 'make a noise while burning' \\
\hline
\end{tabular}

Table 17. Iconic ordering in Kalam complex verbs

\begin{tabular}{lll}
\hline VERB & GLOSS & MEANING \\
\hline d ap- & HOLD COME & 'bring' \\
d am- & HOLD GO & 'take' \\
am d ap- & GO HOLD COME & 'fetch' \\
ap tan jak- & COME ASCEND REACH & 'reach the top' \\
\hline
\end{tabular}

Table 18. Kalam complex verbs with two readings

\begin{tabular}{lll}
\hline VERB & GLOSS & MEANING \\
\hline ap jak am- & COME REACH GO & 'come and go' \\
ap jak am- & COME REACH GO & 'emerge' \\
\hline
\end{tabular}

the means by which the event is carried out. The Kalam verb sequences are argued to be organized temporally, as illustrated in Table 17. However, in some cases, one structure can have two readings, as in Table 18. Only one of the readings is sequential, the other suggest a hierarchical structure in the complex verb.

The variation in meaning suggest that these sequences have a different underlying structure. When ap jak am- means 'come and go', the structure can be read as temporally organized sequence; it can be read as a serialization. When ap jak am- means 'emerge', we find a right-headed derivation with two non-head elements preceding it, specifying the direction and telic properties of the event. We thus suspect that part of the Kalam serialisations may not be serial verbs but could be analyzed as head final derivations, analogous to 
the Abui verbs analyzed in this paper. In that case, Abui will not be the only language that forms new verbs by combining generic verbs with each other.

\begin{abstract}
Abbreviations
$1=$ first person; $1 \mathrm{PE}=$ first person plural exclusive; $1 \mathrm{PI}=$ first person plural inclusive; $2=$ second person; $3 \mathrm{~A}=$ third person Actor; $3 \mathrm{I}=$ third person Undergoer, same referent as Actor; $3 \mathrm{II}=$ third person Undergoer, other referent than Actor; $\mathrm{AD}=$ addressee-based; $\mathrm{AL}=$ alienable $\mathrm{CPL}=$ completive verb stem; $\mathrm{CNT}=$ continuative verb stem; DISTR $=$ distributive; DST $=$ distal; DUR $=$ durative; $I N A L=$ inalienable; $\mathrm{ICP}=$ inceptive verb stem; $\mathrm{LOC}=$ undergoer prefix referring to locations, themes and benefactives; $\mathrm{MD}=$ medial; $\mathrm{P}=$ plural; $\mathrm{PAT}=$ undergoer prefix referring to patients; $\mathrm{PFV}=$ perfective $; \mathrm{PL}=$ plural quantifier $; \mathrm{PRF}=$ perfect $; \mathrm{PROH}=$ prohibitive $; \mathrm{PRX}=$ proximate; $\mathrm{REC}=$ undergoer prefix referring to recipient or goal; RED $=$ reduplication; $\mathrm{S}=$ singular; $\mathrm{SIM}=$ simultaneous linker; $\mathrm{SPC}=$ specific $; \mathrm{TOP}=$ topic $_{\text {marker }}{ }^{1}$
\end{abstract}

\title{
Acknowledgments
}

We would like to thank Geert Booij and Ger Reesink for their comments on previous drafts of this paper. Michael Cysouw as editor of this volume helped us further improve the paper. The Abui data presented comes from the northern dialect of Takalelang. The data has been collected during fieldwork in Alor from 2003 to 2009. Our thanks belong to the Abui community and to our consultants. In particular we want to thank the family of Bapak Timoteus Lanma and to Benidiktus Delpada who is our collaborator in documentation of Abui. The research reported here was conducted as part of the NWO Innovative Research Project 'Linguistic variation in Eastern Indonesia', Leiden University, 2002-2007. Research on Abui that took place after 2007 was supported by La Trobe University, Melbourne.

\section{References}

\footnotetext{
Booij, Geert E.

2005 The grammar of words: an introduction to linguistic morphology. Oxford textbooks in linguistics. Oxford/ New York: Oxford University Press.

Davies, J.

1984 Kobon. Lingua descriptive studies; v. 3. Amsterdam: North-Holland.
} 
Holton, Gary, Marian Klamer and František Kratochvíl

2009 The Languages of Alor and Pantar (Eastern Indonesia): A (re)assessment. Eleventh International Conference on Austronesian Linguistics (11. ICAL), Aussois, France, 22-26 June 2009.

Kratochvíl, František

2007 A grammar of Abui: a Papuan language of Alor. Utrecht: LOT.

Lang, Adrianne

1975 The semantics of classificatory verbs in Enga (and other Papua New Guinea languages). Pacific linguistics; B-39. Canberra: Dept. of Linguistics, Research School of Pacific Studies, Australian National University.

McGregor, William

2002 Verb classification in Australian languages. (Empirical Approaches to Language Typology; 25). Berlin / New York: Mouton de Gruyter.

Pawley, Andrew

1969 The structure of Karam: a grammar of a New Guinea Highlands language. Ph.D. thesis, University of Auckland.

Pawley, Andrew

1987 Encoding events in Kalam and English: Different Logics for Reporting Experience. In: Coherence and grounding in discourse: outcome of a symposium, Eugene, Oregon, June 1984, R. S. Tomlin (ed.), 329-360. Amsterdam/Philadelphia: Benjamins.

Pawley, Andrew

1991 Saying things in Kalam: Reflections on Language and Translation. In Man and a half: essays in Pacific anthropology and ethnobiology in honour of Ralph Bulmer, Andrew Pawley (ed.), 432-444. Auckland: Polynesian Society.

Pawley, Andrew

2001 The Proto Trans New Guinea obstruents: arguments from top-down reconstruction. In The boy from Bundaberg: studies in Melanesian linguistics in honour of Tom Dutton. Tom Dutton et al. (eds.), 261-300. Canberra: Pacific Linguistics.

Pawley, Andrew

2004 Episodic event reports in Kalam: case studies from serial verb and multiclause constructions. Unpublished manuscript.

Pawley, Andrew

2005 A dictionary of Kalam, with ethnographic notes. Unpublished manuscript.

Pawley, Andrew and Jonathan Lane

1998 From event sequence to grammar: serial verb sonstructions in Kalam. In Case, typology, and grammar: in honor of Barry J. Blake, Barry J. Blake, Anna Siewierska and Jae Jung Song (eds.), 201-227. Typological studies in language; 38. Amsterdam/Philadelphia: Benjamins.

Ross, Malcolm

2005 Pronouns as a preliminary diagnostics for grouping Papuan languages. In Papuan pasts: Investigations into the cultural, linguistic and biological history of the Papuan speaking peoples. Andrew Pawley and R. Attenborough (eds.), 15-66. Canberra: Pacific Linguistics. 
Schultze-Berndt, Eva

$2000 \quad$ Simple and complex verbs in Jaminjung: a study of event categorisation in an Australian language. Nijmegen: Max Planck Institute for Psycholinguistics. Spencer, Andrew

1991 Morphological Theory: an introduction to word structure in generative grammar. Cambridge, Mass.: Basil Blackwell.

Stokhof, W. A. L.

1984 Annotations to a text in the Abui language (Alor). Bijdragen tot de taal-, landen volkenkunde 140 (1): 106-162. 